\title{
Eggs as a Very Promising Source of Biomedical and Nutraceutical Preparations: A Review
}

\author{
Tadeusz Trziszka ${ }^{1}$, Henryk Różański ${ }^{2}$ and Antoni Polanowski ${ }^{1}$ \\ 1. Faculty of Food Sciences, Wroctaw University of Environmental and Life Sciences, Wroctaw 51-630, Poland \\ 2. State Higher Vocational School, Krosno 38-400, Poland
}

Received: March 25, 2013 / Accepted: June 17, 2013 / Published: August 30, 2013.

\begin{abstract}
It is generally accepted that eggs besides being a source of everyday diet, can also be used as raw material for special food, nutraceutical, pharmaceutical and cosmetic production. The biological activity of the majority of substances presented in egg matter is related to their anti-microbial and anti-cancer properties and their immunogenic features as well. Due to the use of new generation of feed additives and techniques of immunisation of hens, the chemical composition and biological features of eggs may be modified and enriched with desired components, like n-3 fatty acids (alpha-linolenic acid (ALA), docosahexaenoic acid (DHA) phospholipids), vitamins, microelements. Egg material may also be used for the production of new biopreparations for the prophylaxis of various civilisation diseases, such as heart and cardiovascular diseases, cancers, neurogenerative disorders, metabolic bone diseases etc.. New progress in egg science allowed to discover new bioactive substances, like monomeric and dimeric cystatin and yolkin. It is necessary to develop efficient methods of isolation of biologically active substances contained in eggs, which would make it possible to produce new generation of diet supplements and biomedical products. It seems that new generation of eggs could be the best source for production of natural, high value nutraceutical supplements of diet, and also biomedical and biocosmetic preparations.
\end{abstract}

Key words: Chicken egg, ovoalbumin, lysozyme, immunoglobulin, yolkin, phospholipids.

\section{Introduction}

Nowadays the authors observe growing consumer interest in maintaining good health and slowing the aging process therefore the awareness of people about the role of food in the prevention of diseases and the related tendency to self-medicate with "natural" products seems to be conceivable. The development of functional food market is also affected by nutritionists and doctors, through the media promoting a healthy lifestyle and encouraging prevention.

It is commonly thought that eggs, material of animal origin, are exclusive domain of diet food products and are sometimes consider as a simple, or even primitive, use in food preparation. In highly developed countries, especially, in the USA, Japan, Israel, and EU countries, eggs have always been a

Corresponding author: Tadeusz Trziszka, Ph.D., professor, research fields: food technology and human nutrition. E-mail: tadeusz.trziszka@up.wroc.pl. source of everyday diet as well as raw material used in the pharmaceutical and cosmetic industry. Egg processing is a combination of technological processes in which egg matter is separated from the shell and then, as a whole or, separated into the white and yolk, subjected to a series of technological operations which result in obtaining new products or semi-products [1]. The achievements of molecular biology have a significant influence on the level of innovativeness. Obtaining recombined hen egg proteins characterised by antibacterial activity is of special importance. Two of the identified proteins, i.e. OCX-32 (ovocalixin-32) and OCX-36 (ovocalixin-36), are very promising in this respect. They are present in small amounts in, for example, egg shells and the genes producing them have already been identified and characterized $[2,3]$.

As a result of strong competition on the global markets, which makes pro-innovation measures 
necessary, novel and refined technologies are being implemented. New methods of isolation of bioactive components from eggs, as well as their enzymatic modification or biotransformation using techniques of molecular biology, are looked for $[4,5]$.

There is no any other natural food product which is as perfect as an egg. When a normally laid and fertilized egg is provided with energy in the form of heat $\left(39^{\circ} \mathrm{C}\right)$ for certain period of time, it turns into a living organism (chick) which continues growing and developing. Thus, all substances indispensible for its creation are present in the egg. This fact confirms the excellence of eggs in terms of their biological value [6].

Numerous studies have shown that biological activity of majority of substances contained in egg matter is related to their anti-bacterial, anti-viral, anti-fungal and anti-cancer properties and some possess immunogenic features $[1,4,7,8]$.

That is why hen eggs, so important in food industry, are becoming perfect material to be used in bio-tech, pharmaceutical and cosmetic industry as well. Thanks to the use of new generation of feed additives or techniques of immunisation of hens, the chemical composition and biological features of eggs may be modified and eggs may be enriched with desired components [9-11]. Using layer hens as live bioreactors, for the production of nutraceuticals and biomedical preparations constantly gains popularity. It is well grounded in the biological and economic aspect, as eggs are a perfect reservoir of biocomponents and, at the same time, are a relatively inexpensive material $[1,12]$.

Eggs, both in the non-processed form (consumer eggs), as well as in the processed form (pasteurised egg mass, egg powder, etc.), especially those enriched with bioactive components, may be classified as the so called functional food products characterized by the high content and availability of biologically important compounds and nutrients, including active peptides, proteins, phospholipids, polyunsaturated fatty acids, vitamins and microelements beneficial for human health. Egg material may also be used for the production of new biopreparations used in the prophylaxis of various civilisation diseases, such as heart and cardiovascular diseases, cancers, neurogenerative disorders, metabolic bone diseases (osteoporosis), etc. [1, 13].

Among the protein egg components, there are both active forms, such as lysozyme, serine and cysteine proteinases inhibitors, immunoglobulins, hormones, as well as precursor forms which exhibit specific activities only after proteolytic degradation $[8,14,15]$. Egg yolk lipids, particularly, phospholipids, form a separate group. They are characterized by antioxidative and hypocholerestomeric activity and play an important role in the development and functioning of the nervous system, including the brain [16]. The technologies of their isolation are developed and within this group lecithin is the most important substance because of its nutraceutical and prophylactic properties.

Egg shells (with subshell membranes), as by-products of the industrial processing of eggs, are also worth mentioning [17]. They contain easily absorbed calcium, as well as many microelements such as $\mathrm{B}, \mathrm{Cr}, \mathrm{Cu}, \mathrm{Fe}, \mathrm{I}, \mathrm{Mn}, \mathrm{S}, \mathrm{Se}, \mathrm{Si}, \mathrm{Sr}, \mathrm{V}, \mathrm{Zn}$ and may be used as raw material for the production of calcium preparations (diet supplements) and used in the prophylaxis of osteoporosis [18]. From many substances with scientifically proved therapeutic qualities only a few are produced on an industrial scale. The others, due to their complex process of purification, may be obtained on laboratory scale only. Many of them are characterized by a wide spectrum of antibacterial and anticancer activity.

It is necessary to develop efficient methods of isolation and purification of biologically active constituents of eggs, which would make it possible to produce new pharmaceuticals and nutraceuticals. A lot of attention is paid to the integration of technological processes, including membrane techniques, industrial chromatography and extractions. The modern system 
of extraction in supercritical fluids, including the use of liquid and non-toxic carbon dioxide, is very interesting and innovative. The method may become widely used on the global scale in egg processing, especially in extraction of cholesterol and phospholipids [19-21]. At present, extraction of lecithin from the yolk using ethanol and its purification in hexane-acetone combination is commonly used [22]. However, extraction in the supercritical system allows for precise fractionation of lipid compounds so that the valuable post-extraction proteins may be used for further processing $[19,20,23]$.

The use of enzymatic hydrolysis for modification of the protein components of both egg white and yolk on an industrial scale requires further studies within innovation technologies. New bioactive substances, with various pro-health qualities, obtained in that way may find several practical applications. There are peptides characterized by immunostimulating activity, decreasing blood pressure, reducing platelet aggregation, peptides characterized by antioxidative and antimicrobial activity as well as peptides which are carriers of metal ions [14, 24]. Various types of food proteins may be precursors of biopeptides and the hen egg proteins belong to the richest sources of bioactive peptides $[25,26]$.

\section{Selected Important Biocomponents of Egg Matter}

From among several hundreds of biologically active compounds so far identified and described from hen's egg, only some of them can be isolated in technological processes. This shows, on the one hand, how complex and poorly known are eggs as material for the production of nutraceuticals and biomedical preparations and, on the other hand, how many possibilities and challenges exist for scientific research and advanced technologies.

The main proteins present in egg white and in yolk have been frequently described in various scientific journals, from biological, chemical, functional or technological point of view. Nowadays, new substances with high biological activity (antimicrobial, antioxidant, etc.) which can be used as nutraceutical or biomedical substances are looking for. One of the methods for the creation of this kind of substances is enzymatic digestion of proteins. After this process, a lot of peptides with different bioactivities can be obtained. It seems to be a new trend which, in the future, can be applied on industrial scale. It is commonly thought that some egg proteins have very strong biological activity and they are utilized in practice as biosubstances, for example lysozyme, avidin, immunoglobulin $\mathrm{Y}$ and phosphite. Many scientists are searching now for new polypeptides which can be used in the production of various preparations for many purposes in food, biotechnological and pharmaceutical industry. Below some very important natural and modified egg substances from scientific and practical point of view, which can be of great importance for application and quality of life are presented.

\subsection{Ovalbumin}

Ovalbumin is the main protein in the egg white which constitutes over $50 \%$ of its content. It is the only egg white protein which contains free sulphydryl groups. Ovalbumin shows no protease inhibitory activity despite a $30 \%$ sequence homology with antitrypsin and other functional inhibitors of the serpin family [27]. This protein appeared to be a rich source of new very active products as a result of its proteolytic degradation. The good example is an ovokinin. Ovokinin, a vasorelaxing octapeptide derived from a pepsin digest of ovalbumin, has been shown to significantly lower the systolic blood pressure of spontaneously hypertensive rats. The oral availability of ovokinin is improved after emulsification. As a result of consumption of whole eggs, ovokinin will be released from ovoalbumin by the action of pepsin in the stomach, and the peptide will be instantly emulsified with egg yolk and effectively absorbed from the intestines $[1,28$, 
29]. In fact, it has been reported that some ACE inhibitors have notable effects on oxidative stress and may also contribute to the control of blood pressure by improving endothelial dysfunction. The combined antioxidant and ACE-inhibition properties of the hydrolysate of egg white proteins with pepsin make it a very useful multifunctional preparation for the control of hypertension.

\subsection{Ovotransferrin}

Another constituent of egg white of pharmaceutical interest is ovotransferrin (conalbumin). It is a neutral glycoprotein containing 15 disulfide bridges and a single glycan chain in the C-terminal domain $[6,30]$. Ovotransferrin exists as a covalent dimer protein, composed of an $\mathrm{N}$ - and a C-terminal domain, each one binding one atom of transition metal (Fe[III], $\mathrm{Cu}[\mathrm{III}]$, $\mathrm{Al}[\mathrm{III}]$ ) very tightly and specifically. Ovotransferrin is used for the transport of iron in a soluble form to the target cells. Ovotransferrin after limit proteolysis can be an efficient source of antimicrobial preparations. For example, OTAP-92 (ovotransferrin antimicrobial peptide) is a 92 amino acid cationic fragment of hen ovotransferrin located within the 109-200 sequence of the N-lobe of ovotransferrin. The peptide OTAP-92 showed strong bactericidal activity against both Gram-positive $S$. aureus and Gram-negative E. coli strains. OTAP-92 has also been shown to possess a unique structural motif similar to the insect defenses. Furthermore, this cationic antimicrobial peptide is capable of killing Gram-negative bacteria by crossing the outer membrane by a self-promoted uptake pathway $[1,30]$.

\subsection{Lysozyme}

Lysozyme (N-acetylomuramylohydrolase; EC 3.2.1.17) is one of the proteins characterized by antimicrobial properties and plays a very important role in the natural defense mechanism of humans, animals and plants [31-33]. It is an enzyme with molecular weight of $14.4 \mathrm{kDa}$ and an isoelectric point of 10.7 , whose single polypeptide chain consists of 129 amino acid residues. Lysozyme is a very stable enzyme which, to a large degree, results from the presence of disulfide bonds in a molecule.

Hen egg white is a valuable source of lysozyme which constitutes ca. $3.5 \%$ of its dry mass and it is industrially obtained by means of a combination of ion-exchange and membrane techniques [32].

Monomer is the basic form of lysozyme in nature. However, in suitable temperature conditions, $\mathrm{pH}$ and concentration, it may show tendencies to association. In solutions with weak ionic strength and $\mathrm{pH}$ between 5.0 and 9.0, there appear dimers and oligomers, if $\mathrm{pH}$ is higher than 9.0. From among many forms of thermally and chemically modified lysozyme, dimer has been observed to be the most effective [34].

In its monomeric form, the enzyme is most effective against Gram-positive bacteria strains [35]. It is possible to widen the spectrum of antibacterial activity, also against Gram-negative bacteria, through combined application of lysozyme with such compounds as EDTA (ethylenediaminetetraacetic acid), some organic acids, nisin, lactoferrin, glycine and aprotinin [15]. Moreover, such physical factors as high pressure and increased temperature, which lead to denaturation of proteins, increase the activity of lysozyme against Gram-negative bacteria. The combined use of lysozyme with antibiotics and antiseptics prevents bacteriolysis and the release of bacterial endotoxins and it does not affect the activity of medicines. Lysozyme is also characterized by antiviral activity. It effectively prevents numerous dermal infections, such as herpes, chickenpox or molluscum contagiosum.

By reason of its bacteriocidal and bacteriostatic properties, lysozyme is used as a natural food preservative. It extends the shelf life span of refrigerated poultry meat. When used in fish, meat and milk products, it prevents the growth of Listeria monocytogenes [36]. Lysozyme may also be used for the acceleration of ripening of cheeses. It is due to the 
fact that it causes the lysis of starter bacteria and leads to the release of cytoplasmatic enzymes which play the main role in cheese ripening. As an active additive directly introduced to the packagings, lysozyme extends the durability of non-sterile and non-processed products and prevents the development of microorganisms. Pharmaceutical industry is getting more and more interested in lysozyme as an enzyme which protects the organism from bacterial and viral infections. At present, in the form of pills and aerosols, it is used in the treatment of the respiratory system. Lysozyme preparations preventing tooth decay, periodontitis, inflammation of oral and pharynx mucous membranes are also available. Lysozyme is a component of protective creams used in the treatment of wounds as well as skin and soft tissue defects [35]. There are studies conducted in order to examine the anticancer activity of lysozyme. It has been observed in vitro and in vivo that orally administered lysozyme inhibits the development of many types of cancer, including lung cancer. Although such activity may depend on the immunological response of human organism, direct influence of lysozyme on cancer cells cannot be ruled out [37].

\subsection{Avidin}

Avidin is a protein of size $68.3 \mathrm{kDa}$ and basic in character, pI ca. 10. It constitutes as little as $0.05 \%$ of the content of egg white. Avidin is characterized by antibacterial activity as it binds biotin which is necessary for the development of many microorganisms. It contains carbohydrates and, as the only egg-derivated protein, nucleic acid. The avidin-biotin interaction is characterized by high degree of specificity and affinity (dissociation constant is $\left.0.6 \times 10^{-15} \mathrm{M}\right)$. Moreover, it is not susceptible to many proteolytic enzymes, denaturating agents and organic solvents. The avidin-biotin interaction is one of the strongest known interactions between a protein and organic ligand. Thanks to such features, the avidin-biotin complex is used in biological systems of detection (e.g. Western-blot, ELISA), affinity chromatography, microscopy and nanotechnology. Besides, with four sites binding biotin, avidin guarantees multiplication of the signal and increased sensitivity of the method $[4,38,39]$.

\subsection{Immunoglobulin $Y$}

From among the substances contained in egg yolk, immunoglobulin $\mathrm{Y}(\operatorname{IgY})$, for its therapeutic significance, deserves special attention. Functionally $\operatorname{IgY}$ is an analogue of $\operatorname{IgG}$, the major serum antibody in mammals, though their structures are different. Yolk immunoglobulin is a glycoprotein that contains heavy chain $(60-70 \mathrm{kDa})$ and light chain $(22 \mathrm{kDa})$ and represents about $3 \%$ of yolk dry matter. The heavy chain has four constant domains and one variable domain. The molecular weight of IgY is about 180 $\mathrm{kDa}$ [40]. One hen generally lays about 290 eggs per year which represents $5 \mathrm{~kg}$ of yolk. The level of IgY in yolk ranges from $9 \mathrm{mg} / \mathrm{mL}$ to $25 \mathrm{mg} / \mathrm{mL}$. Egg yolk is a potential source of antibodies for humans because it can be produce on a large-scale [31].

Transport of IgY from blood plasma to egg yolk is by specific receptors located on the yolk membrane. The basic function of $\operatorname{IgY}$ is to ensure proper level of passive immunity of an embryo until its own immunological system is fully developed.

Owing to novel and effective methods of extraction, hen egg yolk antibodies find more and more practical applications. IgY with increased specificity may be obtained after immunisation of hens with a required antigen and then by purification of the immunoglobulin. There are several methods of obtaining such antibodies and, as relatively inexpensive and effective, they are frequently patented $[1,4,15]$. Freeze-dried immunoglobulin preparation may be administered orally as a nutraceutical or food additive. The production of hen antibodies, compared to those obtained from immunised mice, rats, sheep and other animals, has many advantages.

Furthermore, various types of $\operatorname{IgY}$ can be produced 
in large quantities in egg yolk by immunizing hens with specific antigens-proteins, bacteria, viruses, parasites, toxins. Hen antibody production is a good alternative to conventional mammal antibody production because it improves the welfare of animals due to the non-invasive methods of egg collection and yolk isolation [31].

Obtaining of IgY is less invasive, more profitable and, what is the most important, the yield of antibodies from one animal is much larger. One layer hen may produce as much as $40 \mathrm{~g}$ IgY annually, an amount obtained from ca. 40 rabbits [40]. A growing interest in the use of $\operatorname{IgY}$ in therapy and prophylaxis of diseases, as an alternative to the use of antibiotics in the treatment of infections caused by viruses and drug-immune bacteria, has been growing in recent years. The antibodies bind the pathogen and slow down or stop its growth and replication. The prophylactic activity of specific IgY against $P$. aeruginosa infections in the respiratory tract in patients with mucoviscidosis, a frequent genetic diseases of the Caucasians in Europe and USA, is worth special attention. Immunoglobulin $\mathrm{Y}$ is also used in the prevention of tooth decay in humans [1].

\subsection{Phosvitin}

Phosvitin is an interesting protein contained in relatively large amount in egg yolk (ca. $300 \mathrm{mg} /$ yolk). This protein, with a molecular weight of $35 \mathrm{kDa}$, containing $10 \%$ phosphorus and $6.5 \%$ carbohydrates, is considered to be the most phosphorylated glycoprotein found in the nature. Over $57 \%$ of its amino acid composition constitute of serine residues and almost all of them are phosphorylated. As a result, phosvitin shows extremely high metal ion binding capacity, antioxidant activity, emulsifying activity and antimicrobial activity. The phosphorylated serine moieties of phosvitin play major roles with regard to its extraordinary functionalities. Due to the extremely high negative charges, phosvitin forms insoluble metal complexes, resulting them biologically unavailable, and shows extremely high resistance to proteolytic degradation. Nevertheless, upon fragmentetion, the phosphopeptides show enhanced mineral bio-availability, thus its negative attributes can be greatly eliminated. The enzymatic and chemical hydrolyses of phosvitin reduces both antioxidant and calcium and Fe-binding capacities while its $\mathrm{Cu}$-binding ability increases. The $\mathrm{Cu}$-binding capacity of phosvitin is rather poor as compared to its $\mathrm{Fe}^{3+}$-binding ability. However, the hydrolysates showed comparatively good metal binding capacities. Therefore, higher level of phosvitin hydrolysis seems to be desirable if derived phosphopeptides are to be used as calcium or iron supplementing agents for human $[31,41]$.

\section{Hen Egg Bioactive Substances of Particular Importance}

\subsection{Cystatin}

Cystatin from hen egg white is a 116 amino-acid polypeptide with a molecular weight of $13 \mathrm{kDa}$. It contains two disulfide bonds and lacks carbohydrates [38]. Cystatin is an inhibitor of cysteine proteases: papain-like and legumain (asparaginyl endopeptidase 3.4.22.34). Cystatin, present in egg white and, in very low amounts, in egg yolk, regulates the development of an embryo and protects it from cysteine proteases of microorganisms [42].

The concentration of cystatin in serum and in muscles is ca. $1 \mathrm{mg} / \mathrm{L}$, and ca. $80 \mathrm{mg} / \mathrm{L}$ in the white of egg. Due to its low content in egg, extraction of cystatin from it is expensive and not very efficient. Technological preparations for extraction of cystatin, lysozyme and other biosubstances from egg white in an integrated system, i.e. in one technological cycle, are on an advanced level. Ultrafiltration, affinity chromatography and centrifuging technologies are used for isolation. Precipitation and ion-exchange chromatography PIEC (Precipitation and Ion Exchange Chromatography) are used on an industrial scale. Recombined cystatin may also be obtained 
using genetic engineering methods in expression systems of E. coli or Pichia pastoris [43].

As hen cystatin is, in its structure, similar to human cystatin $\mathrm{C}$, it is often used in model medical research. Disorder in the balance between the activity of cysteine proteases and the amount of their inhibitors may result in numerous pathological conditions, including development of carcinomas, muscular atrophy, Alzheimer's diseases, osteoporosis, sclerosis multiplex, chronic inflammations and disorders in the development of epidermis. Multi-directional research is conducted on the use of cystatins as factor which may inhibit proteolytic cascade during cancer [43].

Development of many types of carcinoma is related to high activity of cathepsins and legumain. No expression of cystatin $\mathrm{E} / \mathrm{M}$ has been observed in patients with breast and lung cancer. In physiological conditions, cystatin $\mathrm{E} / \mathrm{M}$ is present in epidermis cells. The study of melanoma cell line showed a correlation between the low level of this cystatin, high proteolytic activity of legumain and the development and metastases of this kind of cancer. This suggests the role of cystatin $\mathrm{E} / \mathrm{M}$ as a suppressor of the development of melanoma [44].

Hen egg cystatin is the first protein in which the process of oligomerisation by three-dimensional domain swapping was observed. Depending on conditions, cystatin may show a tendency to aggregate. Low $\mathrm{pH}$, high temperature and the presence of denaturating agents are favorable for occurrence of a dimer $[43,45]$.

Both in vitro and in vivo studies showed that cystatin prevents oligomerisation and formation of beta-amyloid fibrils. Beta-amyloid reacts only with the dimeric form of cystatin C. Moreover, it is toxic for hippocampus neurons and cortex as it induces the process of oxidation of proteins and lipids and leads to oxidation stress. The formation of beta-amyloid deposits in brain is the key stage in the pathogenesis of Alzheimer disease as it results in neuron disfunction [46].
It has been observed that the inhibitor extracted from egg white is active against various bacteria, viruses and fungi and that it prevents the development of numerous diseases [4].

Cystatin inhibited the growth of Candida parapsilosis and Candida tropicalis at similar concentrations, whereas Candida glabrata was more resistant to this inhibitor [7].

Proteases, including cystein cathepsins, are enzymes which catalyze the hydrolytic cleavage of peptide bonds in protein molecule leading to their degradation or, in case of pro-hormones and pro-enzymes, to the creation of active forms. They are also engaged in the processes of presentation of class II antigens MHC, change of the bone tissue, differentiation of keratinocytes, reproduction and apoptosis. Uncontrolled activity of cathepsins may result in hydrolysis of the wild-type proteins and lead to such pathological conditions as invasion and metastases of cancers, rheumatoid arthritis, osteoporosis, paradontal diseases, dementia, Alzheimer's disease or sclerosis multiplex [47].

The activity of cysteine proteases is regulated by the control of their synthesis on the level of transcription, activation of zymogen and by specific endogenic inhibitors-cystatins [48].

The research on the use of cystatin isolated from hen egg proteins in treating cancer and Alzheimer's disease is advanced [43]. However, the use of cystatin in medicine requires development of concentrated preparations of this protein that will be characterized by high activity and stability.

The problems related to stabilization of cystatin have already been studied. Nakai et al. [49] and Jiang [50] described recombined cystatins stabilized by glycolysation as a result introduction of nucleotide sequence coding $\mathrm{N}$-glycolysation sites compatible with the expression system to the genes of cystatins.

In order to stabilize the structure of a cystatin molecule, storage it at the temperature below $253 \mathrm{~K}$ and with $20 \%$ glycerol, is frequently used [51]. 
The presence of glycerol appeared to be toxic to isolated cell culture so, it must be removed from the solution of cystatin before its applying. Cystatin, however, without any protection, polymerizes and loses its anti-papain activity. The problem of stabilization of cystatin as well as a method of obtaining a concentrate of monomeric cystatin as an inhibitor of cystein proteases has been recently solved [52]. It was observed that cystatin may be stabilized by a properly composed buffering solution and an addition of stabilizers other than glycerol. Solutions of bovine albumin and selected saccharides at the final concentration between $1 \%$ and $5 \%$ may be used as stabilizer. It is favorable to remove glycerol through dialysis against the solution of stabilizers prior to final purification or concentration of the inhibitor. The main advantage of such a method is that the preparation obtained is stable, free of glycerol, with the specific activity over $10 \mathrm{U} / \mathrm{mg}$ protein and a concentration up to $5 \mathrm{mM}$. Results of the study may be practically used in pharmaceutical, cosmetics and food industry.

\subsection{Yolkin}

The significant progress made recently in explaining the molecular principles of pathogenesis of neurodegenerative diseases turned the researchers' attention to a new group of protein substances which are characterized by regulatory properties against the cells of the central nervous system and which may thus be important in therapeutics. Numerous transmitters are necessary for the communication between glial and lymphoid cells, among which cytokines are those which have recently been intensively studied [53, 54].

The peptides which are characterized by immunomodulatory properties against such neurodegenerative diseases as, e.g. Alzheimer's disease (AD) are especially important from the therapeutic point of view. Bioactive peptides may exist in a free state, completed with other substances, or may be a structural element of larger proteins from which they are removed during proteolysis.

A complex of PRP (prolin rich polypeptides) isolated for the first time from sheep colostrum is a good example of such compounds. The complex, later

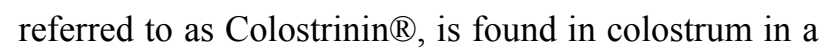
form bound with a fraction of immunoglobulins $\operatorname{IgG} 2$, which indicates its immunotropic properties [55]. Colostrinin (CLN) is a strong inductor of secretion of cytokines so vital for the immune system, i.e. interferone- $\gamma$ (INF- $\gamma$ ) and TNF- $\alpha$ as well as interleukin IL-6 and IL-10 [56].

Taking into consideration the formation of colostrum and egg yolk, a hypothesis about the biological identity of substances with immunomodulatory features present in colostrum (Colostrinin) and in egg yolk was postulated. Based on it the authors have shown that hen egg yolk IgY preparation, the main immunoglobulin class of the avian immune system, indeed, is capable of stimulating whole blood cells to release TNF- $\alpha$ and IL-1 $\beta$ cytokines [57]. The results obtained in the study suggested that IgY, like the colostral IgG, may be accompanied by some substances exhibiting properties similar to those of colostral PRP. When, the native IgY preparation, isolated from the plasmatic fraction of hen egg yolk, was subjected to size exclusion chromatography, under dissociating conditions, two distinct protein fraction were separated. Alongside IgY, a fraction of low molecular weight proteins was obtained. In cytokine induction experiments, it was shown that this protein fraction, named yolkin exhibited much higher inducing activity then a sample of additionally co-purified IgY. Obtained preparation was found to be a heterogenous mixture of peptides and proteins of molecular weight ranging from over $1 \mathrm{kDa}$ to $35 \mathrm{kDa}$, in which peptides of size about $16 \mathrm{kDa}$ and $23 \mathrm{kDa}$, as judged by SDS-PAGE, are most abundant. It is noteworthy that each fraction separated by means of RF-HPLC, irrespective of size, displayed significant 
immunostimulating activity. In contradiction to Colostrinin, it does not belong to high proline proteins. It contains as little as $6.31 \%$ of this amino acid and is characterized by a relatively high content of acidic amino acids and a low content of methionin. The preparation, resembles, nevertheless, Colostrinin in terms of immunoregulatory properties. Like Colostrinin, it appeared to be a strong inductor of secretion of cytokines (IL-1 $\beta$ and IL-6INF- $\gamma$ and TNF- $\alpha$,), so important for the immunological system. Amino acid sequence analysis revealed that all constituents of yolkin were derived from the C-terminal fragment of the major yolk precursor protein vitellogenin. This finding reveals a new role for vitellogenin as a reservoir of polypeptides which may play an important role in the innate immune system of the developing embryo [58].

\section{NGPL (New Generation of Phospholipids) Rich in Long PUFAs}

Among non-protein substances contained in egg yolk, the most important - both for pharmacology and food industry-are phospholipids, that constitute over $22 \%$ of its dry mass. The main phospholipids contained in the yolk are phosphocholine (lecithin) (80.5\%) and phosphatidylethanolamine (cephaline) (19.1\%). An average yolk from hen egg (ca. $16 \mathrm{~g}$ ) contains about $2 \mathrm{~g}$ of great value phospholipids. Lecithin (phosphocholine) is a crucial component of the structure of all cell membranes and apart of that, as a perfect source of active choline plays a very important role in physiology of organisms. It is a source of diacyloglycerol and fatty acids which participate in intracellular communication and regulate the activity of hormones, growth factors and neurotransmitters. As an element of diet, it is used as an aid in the treatment and prevention of many health disorders. The cells deprived of lecithin are characterized by hardening of the membrane resulting in disorders in the biological transport of metabolites and in the absorption of nutrients. Lecithin is also necessary in the metabolism of methyl residues, cholinergic transfer of nerve impulses, and transfer of intercellular impulses, while regulating the level of cholesterol and triacylglycerols in blood, prevents building up of these compounds on the walls of blood vessels and reduces the risk of vascular diseases. It is also widely believed that lecithin and choline increase the functioning of brain, improve the process of memorising and the ability to concentrate. Moreover, they help in digestion of fats and inhibit their build-up in the liver, prevent fatty liver, increases the effect of antioxidative vitamins, prevent tumours and improve the physical ability of human body $[4,21,59,60]$. Although, since the 30 's of the previous century, soya and rape seeds have been the main source of lecithin, egg yolk lecithin is, due to its unique chemical composition, an important alternative source of this substance. Egg yolk phosphocholine differs from the lecithin of plant origin in the content of unsaturated fatty acids significant for human organism: AA (arachidonic acid) and DHA (docosahexaenoic acid). Arachidonic acid takes part in the transmission of intercellular signals and is responsible for the condition of the cell membrane. Docosahexaenoic acid is necessary for the proper development of brain, nervous system and the processes of seeing. From the pharmacological point of view, soybean lecithin, which does not contain these acids, can not replace egg yolk phosphocholine [4, 21, 37]. Moreover, the content of AA and DHA may be increased through a proper feeding programme of the layer hens. Research programmes have been conducted for many years in order to enrich eggs with omega-3 fatty acids and to increase the content of long-chain fatty acids (L-PUFA) in the yolk [9, 11, 61-64]. Such enriched eggs are referred to as designed eggs and phospholipids extracted from them are unique as they contain DHA (docosahexaenoic acid) built in the sn-2 position. Thus, they may be used for the production of lecithin rich in DHA. As mentioned above, phospholipids play a very important role in 
functioning of every live system. They are found in all living cells, both plant and animal. In humans and in animals, the phospholipids are concentrated in the vital organs, such as the brain, liver, and kidney; in vegetables, their highest content was determined in the seeds, nuts, and grains [65]. Phospholipids are participants in metabolic processes and major components of plasma membrane and organelle membranes that maintain the integrity of the cell or organelles by creating a semi-impermeable barrier from their outside environment $[12,60]$.

Phospholipids which are made of glycerol, fatty acids and other functional substances, include: phosphatidylcholine

(lecithin), phosphatidylethanolamine (cephalin), phosphatidylinositol and phosphatidylserine. The example of the structure of important phospholipids is presented in Fig. 1.

From the nutritional point of view, one of the most important features of phospholipids is their fatty acid profile. Biologically active PUFA (polyunsaturated fatty acids) from n-3 and n-6 family are most beneficial to human health from all fatty acids found in food. They are components of cell membranes and precursors of eicosanoids [66]. They have a positive effect on cardiovascular system by lowering the cholesterol level, decreasing of triacylglicerols synthesis, inhibiting of platelet aggregation and

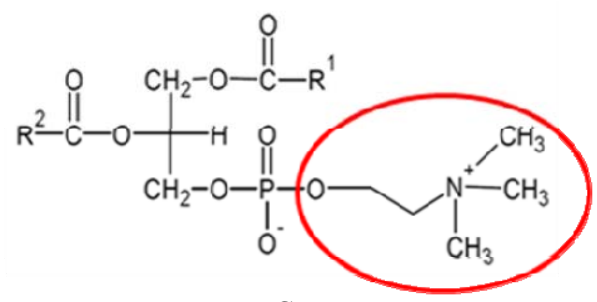

PC lowering the blood pressure [64, 67, 68,]. (DHA (Docosahexaenoic acid), 22:6, n-3) and (EPA (eicosapentaenoic acid), 20:5, n-3) are necessary in brain and eyesight development $[69,70]$. The PUFAs, especially $\gamma$-linolenic acid (GLA, 18:3, $n$-3), prevent skin from atopic dermatitis, psoriasis, acne and skin allergy [71].

A new generation of yolk phospholipids obtained from enriched eggs - super lecithin rich in DHA has been recently described $[5,10,21,72$,$] . It was$ observed that PUFAs from feed were built in position sn-2 of the yolk phospholipids, but the coefficient of incorporation was higher in cephalin than in lecithin, as shown in Tables 1 and 2.

Schreiner et al. [73] described the effect of feeding laying hens seal blubber oil on the fatty acid profile in egg lipids. The authors stated that DHA, EPA and DPA were found predominantly in phospholipid fractions, but their content in TAG was also significant and increased when more than $1.25 \%$ of oil was added to diet. Besides, similarly to our results, the content of DHA in PE was higher than in PC and DHA and was found almost entirely in sn-2 position of $\mathrm{PC}$ and $\mathrm{PE}$, replacing arachidonic acid.

Research programmes in main research centres have been conducted for many years in order to enrich eggs with omega-3 fatty acids and to increase the content of long-chain fatty acids (L-PUFA) in the yolk.

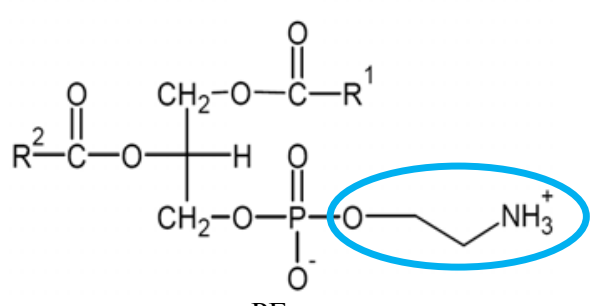

PE

Fig. 1 Chemical structure of a phospholipid—phosphatidylcholine (lecitin, PC) and phosphatidyloetanoloamine (cephalin, PE).

Table 1 The positional distribution of fatty acids in egg yolk phospholipids fractions from the experimental group of Lohmann Brown hens [10].

\begin{tabular}{|c|c|c|c|c|c|c|c|c|c|}
\hline Phospholipid fraction & Position of glycerol backbone & $16: 0$ & $16: 1$ & $18: 0$ & $18: 1$ & $18: 2$ & $18: 3$ & $20: 4$ & $22: 6$ \\
\hline \multirow{2}{*}{$\mathrm{PC}$} & sn-1 & 74.3 & 2.81 & 18.3 & 3.32 & 1.23 & nd & nd & nd \\
\hline & sn-2 & nd & nd & nd & 36.1 & 29.3 & 9.09 & 11.4 & 14.1 \\
\hline \multirow{2}{*}{ PE } & sn-1 & 32.1 & nd & 64.9 & 3.03 & nd & nd & nd & nd \\
\hline & sn-2 & nd & nd & nd & 26.1 & 19.1 & nd & 12.7 & 42.1 \\
\hline
\end{tabular}

Results expressed as percentage of the total fatty acids; nd, not detected. 
Table 2 The fatty acid composition and n-6/n-3 ratio of egg yolk lipid fractions from two groups of Lohmann Brown hens [10].

\begin{tabular}{|c|c|c|c|c|c|c|c|c|c|c|c|}
\hline Entry & Fraction & Group & $16: 0$ & $16: 1$ & $18: 0$ & $18: 1$ & $18: 2$ & $18: 3$ & $20: 4$ & $22: 6$ & $n-6 / n-3$ \\
\hline & & Control & $36.1 \mathrm{a}$ & $0.98 \mathrm{a}$ & $14.4 \mathrm{a}$ & $24.3 a$ & $19.3 \mathrm{a}$ & nd & $3.60 \mathrm{a}$ & $1.18 \mathrm{a}$ & $19.5 \mathrm{a}$ \\
\hline 3 & PC & Experimental & $29.8 b$ & $0.95 \mathrm{a}$ & $17.4 \mathrm{~b}$ & $26.4 b$ & $16.4 b$ & $0.78 \mathrm{~b}$ & $2.15 b$ & $6.28 \mathrm{~b}$ & $2.6 b$ \\
\hline 4 & $\mathrm{PE}$ & $\begin{array}{l}\text { Control } \\
\text { Experimental }\end{array}$ & $\begin{array}{l}21.5 \mathrm{a} \\
15.4 \mathrm{~b}\end{array}$ & $\begin{array}{l}\text { nd } \\
0.37 b\end{array}$ & $\begin{array}{l}28.5 \mathrm{a} \\
33.4 \mathrm{~b}\end{array}$ & $\begin{array}{l}19.2 \mathrm{a} \\
16.4 \mathrm{~b}\end{array}$ & $\begin{array}{l}16.8 \mathrm{a} \\
9.25 \mathrm{~b}\end{array}$ & $\begin{array}{l}\mathrm{nd}^{\mathrm{b}} \\
\mathrm{nd}^{\mathrm{b}}\end{array}$ & $\begin{array}{l}10.9 \mathrm{a} \\
6.62 \mathrm{~b}\end{array}$ & $\begin{array}{l}2.78 \mathrm{a} \\
19.1 \mathrm{~b}\end{array}$ & $\begin{array}{l}9.9 \mathrm{a} \\
0.8 \mathrm{~b}\end{array}$ \\
\hline
\end{tabular}

Results expressed as percentage of the total fatty acid; nd, not detected.

Such enriched eggs are referred to as designed eggs and phospholipids extracted from them are unique as they have DHA (docosahexaenoic acid) built in the sn-2 position. Thus, they may be used for the production of "NGPL (new generation phospholipids)" or "SLC (super lecithin)" rich in DHA.

Crucial effect on human health have a ratio of n- $6 / n-3$ fatty acids [12, 64, 66]. Recent studies showed that optimal n-6/n-3 ratio in diet should fluctuate between $1: 1$ and 4:1 [12, 63, 64, 66]. Unfortunately, at present, the authors can observe the increase of consumption of $\mathrm{n}-6$ acids in comparison to $\mathrm{n}-3$ ones. Aforementioned ratio reaches the value over $15: 1$, which can cause disfunctions of immunological system and higher susceptibility to inflammatory condition [64, 66, 74]. Eggs are a rich source of n-3 PUFA acids in human diet because their fatty acid composition can be easily changed by modifications of feeding of laying hens [75]. Studies revealed that adding natural sources of n-3 PUFA to hen feed significantly enriches egg yolk lipids with these acids [76]. An increase in application of humic materials in animal feeding has recently been observed. They can be used for the production of dietary humic acids and huminates. Together with the plant and fish oils they can also be components of various humine-fat feed additives. Humine preparations are produced in Germany (Humin-feed), Australia (Humex) and Great Britain (Humet). Humic-mineral preparation Humokarbowit- $\mathrm{Hkw}$ and humine-fat preparation Humobentofet- $\mathrm{Hbf}$ are produced in Poland [77, 78]. The humine additives generally have a positive influence on the production results, the health status of laying hens and the quality of chicken eggs from intensive [79, 80] as well as from ecological and extensive breeding systems [81, 82] studied the application of Humokarbowit and Humobentofet enriched with fish oil and linseed oil in feeding Lohmann Brown laying hens. In phase III of the laying period they observed an overall increase of egg-yolk fat and better fatty acid profile in egg-yolk total lipids. Gładkowski et al. [10, 21] indicated a strong effect of the humine-fat supplements on the composition of egg-yolk phospholipids and also the fatty acids composition not only in crude phospholipid fraction, but also on the distribution of fatty acids between triacylglycerol fraction (TAG) as well as phosphatidylcholine (PC) and phosphatidylethanolamine (PE).

Generally, NGPL (new generation phospholipids), rich in n-3 fatty acids, especially in DHA, may be produced only from designed eggs. First of all, the authors have to use a special feeding system with feed additives, like humine-fat preparation, algae, fish oil and flaxseed. This kind of eggs can be processed using innovative technology in order to obtain high value phospholipids, which can be applied in nutraceutical or bio-medical preparations [11].

Pure egg yolk phospholipids have found their use in cosmetics and pharmaceutical applications, especially in emulsion and liposome formulation [1].

\section{Conclusions}

A number of egg proteins have demonstrated antimicrobial, anticancer, antihypertensive and immunomodulatory activities. That is why hen eggs may be used for the production of new biopreparations used in the prophylaxis of various civilisation diseases. Among them there are both active forms, such as lysozyme, serine and cysteine proteinases inhibitors, immunoglobulins, hormones, as well as precursor forms 
which exhibit activities only after proteolysis. Only a few compounds of hen's egg, can be isolated in technological processes. Ovokinin, a peptide fragment of egg white ovalbumin, possesses combined antioxidant and angiotensin I-converting enzyme inhibition properties. Another constituents of egg white of pharmaceutical interest are avidin, ovotransferrin (conalbumin), lysozyme and cystatin. Avidin is characterized by antibacterial activity as it binds biotin which is necessary for the development of many microorganisms. The avidin-biotin interaction is one of the strongest known interactions between a protein and organic ligand. Thanks to such features, the avidin-biotin complex is used in biological systems of detection (e.g. Western-blot, ELISA), affinity chromatography, microscopy and nanotechnology. Ovotransferin, originally being a carrier of iron in a soluble form to the target cells, after limited proteolysis, yields a peptide, OTAP-92, exhibiting strong bactericidal activity against both Gram-positive $S$. aureus and Gram-negative E. coli strains. Lysozyme is one of the proteins characterized by antimicrobial and antiviral properties and plays a very important role in the natural defense mechanism. It effectively prevents numerous dermal infections, such as herpes, chickenpox or molluscum contagiosum. It has been observed that orally administered lysozyme inhibits the development of many types of cancer, including lung cancer. Due to its bacteriocidal and bacteriostatic properties, lysozyme is used as a natural food preservative.

Cystatin is an inhibitor of cystein proteases exhibiting as well strong antimicrobial and antiviral activities. Disorder in the balance between the activity of cysteine proteases and the amount of their inhibitors may result in numerous pathological conditions, including development of carcinomas, muscular atrophy and Alzheimer's diseases. Development of many types of carcinoma is related to high activity of cathepsins and legumain. Studies showed that cystatin prevents oligomerisation and formation of beta-amyloid fibrils which are the key stage in the pathogenesis of Alzheimer disease. However, the use of cystatin in medicine requires development of concentrated preparations of high activity and stability. In order to stabilize the structure of a cystatin molecule, storage it at the temperature below $253 \mathrm{~K}$ and with $20 \%$ glycerol, is frequently used. Glycerol appeared to be toxic to isolated cell culture so, it must be removed from the solution of cystatin before its applying. Cystatin, however, without any protection, polymerizes and loses its activity. It has been found that the activity of cystatin may be stabilized either by producing recombined protein stabilized by glycolysation or by applying, during separation of cystatin from egg white, a properly composed buffering solution containing bovine albumin and selected saccharides (1\%-5\%) as stabilizers.

Studying the molecular principles of pathogenesis of neurodegenerative diseases the researchers have shown that among numerous transmitters involved in the communication between glial and lymphoid cells, cytokines play an essential role. Consequently, the peptides which are characterized by immunomodulatory properties against such neurodegenerative diseases as e.g. AD (Alzheimer's disease) are especially important from the therapeutic point of view. A complex of PRP (prolin rich polypeptides), later referred to as Colostrinin ${ }^{\circledR}$, found in colostrum in a form bound with a fraction of immunoglobulins IgG2, is a good example of such compounds. Colostrinin (CLN) is a strong inductor of secretion of cytokines so vital for the immune system, (i.e. INF- $\gamma$, TNF- $\alpha$ as well as interleukin IL-6).

The contents of an egg are as important for the developing birds as colostrum for newborn mammals. Among the egg yolk components, the most important is the main yolk IgY. Due to $\mathrm{pH}$ and proteolysis stability, IgY antibodies are very useful for passive immunization therapy through oral ingestion. Antigen-specific IgY can be produced on a large scale from eggs laid by hens immunized with selected antigens. Assuming that the function of colostrum for 
newborn mammals, in respect to immunological activity, is similar to the function of the egg yolk for developing birds, it was interesting to find out whether IgY occurs as a complex with peptides exhibiting immunostimulating properties similar to those of Colostrinin. It was found that $\operatorname{IgY}$, indeed, like the colostral $\mathrm{IgG}$, is accompanied by a heterogenous mixture of peptides (named Yolkin) of MW ranging from over $1 \mathrm{kDa}$ to $35 \mathrm{kDa}$, exhibiting properties similar to those of colostral PRP. It is noteworthy that each fraction separated by means of RF-HPLC, irrespective of size, appeared to be a strong inductor of secretion of cytokines (IL-1 $\beta$ and IL-6INF- $\gamma$ and TNF- $\alpha$ ). Amino acid sequence analysis revealed that all constituents of yolkin were derived from the C-terminal fragment of the major yolk precursor protein vitellogenin. This finding reveals a new role for vitellogenin as a reservoir of polypeptides which may play an important role in the innate immune system of the developing embryo.

Among non-protein substances contained in egg yolk, the most important-both for pharmacology and food industry - are phospholipids, that constitute over $22 \%$ of its dry mass. The main phospholipids contained in the yolk are phosphocholine (lecithin) (80.5\%) and phosphatidylethanolamine (cephaline) (19.1\%). An average yolk from hen egg (ca. 16 g) contains about $2 \mathrm{~g}$ of great value phospholipids. Lecithin (phosphocholine) is a crucial component of the structure of all cell membranes and a part of that, as a perfect source of active choline plays a very important role in physiology of organisms. As yet, soya and rape seeds have been the main source of lecithin, egg yolk lecithin is, due to its unique chemical composition, an important alternative source of this substance. Egg yolk phosphocholine differs from the lecithin of plant origin in the content of unsaturated fatty acids significant for human organism: AA (arachidonic acid) and DHA (docosahexaenoic acid). Arachidonic acid takes part in the transmission of intercellular signals and is responsible for the condition of the cell membrane. Docosahexaenoic acid is necessary for the proper development of brain, nervous system and the processes of seeing. Thanks to the use of new generation of feed additives or techniques of immunization of hens, the chemical composition and biological features of eggs may be modified and eggs may be enriched with desired components like n-3 fatty acids (ALA, DHA phospholipids) vitamins, microelemnts. Egg yolk lipids, particularly, phospholipids, are characterized by antioxidative and hypocholerestomeric activity and play an important role in the development and functioning of the nervous system, including the brain.

From the nutritional point of view, one of the most important features of phospholipids is their fatty acid profile. Biologically active polyunsaturated fatty acids (PUFA) from n-3 and n-6 family are most beneficial to human health from all fatty acids found in food. A new generation of yolk phospholipids obtained from enriched eggs - super lecithin rich in DHA has been recently described. It was observed that PUFAs from feed were built in position sn-2 of the yolk phospholipids, but the coefficient of incorporation was higher in cephalin than in lecithin. Generally, NGPL (new generation phospholipids), rich in n-3 fatty acids, especially in DHA, may be produced only from designed eggs. Pure egg yolk phospholipids have found their use in cosmetics and pharmaceutical applications, especially in emulsion and liposome formulation. From many substances with scientifically proved therapeutic qualities only a few are produced on an industrial scale. A lot of attention is paid to the integration of technological processes. The modern system of extraction in supercritical fluids, including the use of liquid and non-toxic carbon dioxide, allows for precise fractionation of lipid compounds so that the valuable post-extraction proteins may be used for further processing.

\section{Acknowledgments}

Performed during the realization of project No. 
POIG.01.03.01-00-133/08- - Innovative technologies of production of biopreparations based on new generation egg (OVOCURA)". The project is co-financed by the European Regional Development Fund within the Innovative Economy 2007-2013 Operational Programme.

\section{References}

[1] R. Schade, Use of eggs for human/animal health and biotechnology, in: R. Huopalahti, R. López-Fandiño, M. Anton, R. Schade (Eds.), Bioactive Egg Compounds, Springer-Verlag, Berlin Heidelberg, Germany, 2007, pp. 191-290.

[2] J. Gautron, M.T. Hincke, K. Mann, M. Panheleux, M. Bain, M.D. McKee, et al., Ovocalyxin-32, a novel chicken eggshell matrix protein, Isolation, amino acid sequencing, cloning, and immunocytochemical localization, J. Biol. Chem. 276 (2001) 39243-39252.

[3] J. Gautron, E. Murayama, A. Vignal, M. Morisson, M.D. McKee, S. Rehault, et al., Cloning of ovocalyxin-36, a novel chicken eggshell protein related to lip polysaccharide-binding proteins, bactericidal permeability-increasing proteins, and plunc family proteins, J. Biol. Chem. 282 (2007) 5273-5286.

[4] A. Sosnowska, T. Trziszka, A. Polanowski, F. Bubel, Bioactive substances of hen eggs, Their biomedical importance and technological possibility for production in an industrial scale, Przemysł Chemiczny 90 (2011) 1029-1034. (in Polish)

[5] T. Trziszka, Application of modern technologies for manufacturing nutraceuticals from designed eggs, Book Abstracts: XIV European Symposium on the Quality of Eggs and Egg Products, Leipzig, Sept. 4-8, 2011, World Poultry Science Journal 67 (2011) 42-43.

[6] T. Trziszka, Egg science and technology, Academic Editing Wroclaw Agricultural University, 2000. (in Polish)

[7] A. Kołaczkowska, A. Sokołowska, H. Miecznikowska, K. Rolka, A. Polanowski, The antifungal properties of chicken egg cystatin against Candida yeast isolates showing different levels of azole resistance, Mycoses 53 (2010) 314-320.

[8] A. Bambrowicz, M. Żelazko, T. Trziszka, Hen egg proteins: Precursors of bioactive peptides, Medycyna Wet. 67 (2011) 157-161. (in Polish)

[9] P.F Surai, N.H.C. Sparks, Designer eggs: From improvement of egg composition to functional food, Trends in Food Sci. Technol. 12 (2000) 7-13.

[10] W. Gładkowski, G. Kiełbowicz, A. Chojnacka, M. Gil, T. Trziszka, Z. Dobrzanski, et al., Fatty acid composition of egg yolk phospholipid fractions following feed supplementation of Lohmann Brown hens with humic-fat preparations, Food Chemistry 126 (2011) 1013-1018.

[11] T. Trziszka, Z. Dobrzanski., M. Kaźmierska, L. Tronina, M. Skiba, Effect of dietary humic-fatty preparations on egg quality in Lohmann Brown hens, Arch. Geflugelk. 75 (2011) 84-90.

[12] N. Shapira, Every egg may have a targeted purpose: Toward a differential approach to egg according to composition and functional effect, World's Poultry Science Journal 66 (2010) 271-284.

[13] R. López-Fandiño, Use of egg compounds for human nutrition, in: R. Huopalahti, R. López-Fandiño, M. Anton, R. Schade (Eds.), Bioactive Egg Compounds, Springer-Verlag, Berlin Heidelberg, Germany, 2007, pp. 117-190.

[14] Y. Mine, J. Kovacs-Nolan, New insights in biologically active proteins and peptides derived from hen egg, World Poult. Sci. J. 62 (2006) 87.

[15] Y. Mine, Egg proteins and peptides in human health-chemistry, bioactivity and production, Curr. Pharm. Des. 13 (2007) 875-884.

[16] G. Pepeu, Is there evidence that phospholipid administration is beneficial for your brain, in: B.F. Szuhaj, W. van Nieuwenhuyzen (Eds.), Nutrition and Biochemistry of Phospholipds, AOCS Press, USA, 2003, pp. 30-39.

[17] Y. Masuda, Hen's eggshell calcium, Clin. Calcium 15 (2005) 95-100.

[18] B. Dolińska, A. Mikulska, S. Dragan, Z. Dobrzański, T. Trziszka, F. Ryszka, Technology and chemical composition of calcium preparation made of hen's eggshell and dolomite, Przem. Chemiczny 90 (2011) 726-730. (in Polish)

[19] H. Aro, Extraction of several eggs compounds at a pilot scale, in: R. Huopalahti, R. López- Fandiño, M. Anton, R. Schade (Eds.), Bioactive Egg Compounds, Springer-Verlag, Berlin Heidelberg, Germany, 2007, pp. 241-246.

[20] L. Bobak, T. Trziszka, M. Kaźmierska, E. Rój, D. Kostrzewa, K. Grzęda, A method for production of lecithin preparation from hen's egg yolk, PL Patent Application, P 389-655 (2009).

[21] W. Gładkowski, A. Chojnacka, G. Kiełbowicz, T. Trziszka, C. Wawrzeńczyk, Isolation of pure phospholipids fraction from egg yolk, J. Am. Oil Chem. Soc. 89 (2012) 179-182.

[22] L.E. Palacios, T. Wang, Extraction of egg-yolk lecithin, J. Am. Oil Chem. Soc. 82 (2005) 565-569.

[23] W. Gładkowski, G. Kiełbowicz, A. Chojnacka, B. Pisarski, C. Wawrzeńczyk, Isolation of phospholipids from lyophilized hen egg yolks, Przem. Chem. 89 (2010) 352-355. (in Polish)

[24] R. Hartman, H. Miesel, Food-derived peptides with biological activity: From research to food applications, Cur. Opin. in Biotechnol 18 (2007) 163-169.

[25] A. Pellegrini, U. Thomas, P. Wild, E. Schraner, R. Von 
Fellenberg, Effect of lysozyme or modified lysozyme fragments on DNA and RNA synthesis and membrane permeability of Echerichia coli, Microbiol. Research. 155 (2000) 69-77.

[26] N. Tsuge, Y. Eikawa, Y. Nomura, M. Yamamoto, K. Sugisawa, Antioxidative activity of peptides prepared by enzymatic hydrolysis of egg white albumin, Nippon Nogeikagaku Kuishi. 65 (1991) 1635-1641.

[27] V. Lechevalier, T. Croguennec, F. Nau, Ovoalbumin and gene-related proteins, in: R. Huopalahti, R. López-Fandiño, M. Anton, R. Schade (Eds.), Bioactive Egg Compounds, Springer-Verlag, Berlin Heidelberg, 2007, pp. 51-60.

[28] A. Davalos, M. Miguel, B. Bartolome, R. López-Fandiño, Antioxidant activity of peptides derived from egg white proteins by enzymatic hydrolysis, J. Food Prot. 67 (2004) 1939-1944.

[29] M. Miguel, A. Aleixandre, Antihypertensive peptides derived from egg proteins, The Journal of Nutrition 136 (2006) 1457-1460.

[30] F. Superti, M.G. Ammendolia, F. Berlutti, Ovotransferin, in: R. Huopalahti, R. López-Fandiño, M. Anton, R. Schade (Eds.), Bioactive Egg Compounds, Springer-Verlag, Berlin Heidelberg, 2007, pp. 43-50.

[31] M. Anton, F. Nau, Y. Nys, Bioactive egg components and their potential uses, World's Poultry Sciences Journal 62 (2006) 429-438.

[32] G. Lesnierowski, J. Kijowski, Lysozyme, in: R. Huopalahti, R. López-Fandiño, M. Anton, R. Schade (Eds.), Bioactive Egg Compounds, Springer-Verlag, Berlin Heidelberg, 2007, pp. 33-42.

[33] G. Leśnierowski, New ways of physico-chemical modification of lysozyme, Nauka Przyr. Technol. 3 (2009) 1-18. (in Polish)

[34] R. Cegielska-Radziejewska, G. Leśnierowski, J. Kijowski, T. Szablewski, J. Zabielski, Effects of treatment with lysozyme and its polymers on the microflora and sensory properties of chilled chicken breast muscles, Bull. Vet. Inst. Pulawy 53 (2009) 455-461

[35] P. Ratajczak, W. Białas, R. Dembczyński, W. Grajek, T. Jankowski, An aqueous two-phase extraction of lysozyme from egg white, Żywność. Nauka. Technologia. Jakość 3 (2004) 40-52. (in Polish)

[36] R. Dembczyński, W. Białas, T. Jankowski, Application of aqueous two-phase extraction to separate lysozyme from hen egg white, Żywność. Nauka. Technologia. Jakość 5 (2009) 5-17. (in Polish)

[37] J. Kovacs-Nolan, M. Phillips, Y. Mine, Advances in the value of eggs and egg components for human health, J. Agric. Food Chem. 53 (2005) 8421-8431.

[38] K. Gołąb, M. Warwas, chicken egg proteins-biochemical properties and applications, Adv. Clin. Exp. Med. 14 (2005) 1001-1010. (in Polish)

[39] F. Nau, C. Guérin-Dubiard, Avidin, in: R. Huopalahti, R.
López-Fandiño, M. Anton, R. Schade (Eds.), Bioactive Egg Compounds, Springer-Verlag, Berlin Heidelberg, 2007, pp. 287-292

[40] J. Kovacs-Nolan, Y. Mine, Avian egg antibodies: Basic and potential applications, Avian Poultry. Biol. Rev. 15 (2004) 25-46.

[41] S.M.C. Himali, Production and characterization of phosphopeptides from egg yolk phosvitin, Graduate Theses and Dissertations, Iowa State University, 2012, p. 12451.

[42] I. Saxena, S. Tayyab, Protein proteinase inhibitors from avian egg whites, Cell Mol. Life Sci. 53 (1997) 13-23.

[43] K. Gołąb, A. Horowski, M. Warwas, Hen cystatin as a model protein in medicine, Farm. Pol. 64 (2008) 759-769. (in Polish)

[44] J.J. Briggs, M.H. Haugen, H.T. Johansen, A.I. Riker, M. Abrahamson, Ø. Fodstad, et al., Cystatin E/M supresses legumain activity and invasion of human melanoma, BMC Cancer 10:17, 2010. DOI: 10.1186/1471-2407-10-17.

[45] K. Gołąb, J. Gburek, K. Juszczyńska, T. Trziszka, A. Polanowski, Stabilization of monomeric chicken egg white cystatin, Przemysł Chemiczny 91 (2012) 174-179. (in Polish)

[46] B. Tizon, E.M. Ribe, W. Mi, C.M. Troy, E. Levy, Cystatin C protects neuronal cells from amyloid- $\beta$-induced toxicity, J. Alzheimer's Disease 19 (2010) 885-894.

[47] O. Vasiljeva, T. Reinheckel, C. Peters, D. Turk, V. Turk, B. Turk, Emerging roles of cysteine cathepsins in disease and their potential as drug targets, Cur. Pharm. 13 (2007) 385-401.

[48] Z. Grzonka, E. Jankowska, F. Kasprzykowski, R. Kasprzykowska, L. Łankiewicz, W. Wiczk, et al., Structural studies of cysteine proteases and inhibitors, Acta Biochim. Polon. 48 (2001) 1-20.

[49] S. Nakai, M. Ogawa, S. Nakamura, Production and use of modyfied cystatin, US Patent, 6534477 B2 (2006).

[50] S.T. Jiang, Temperature-stable glycosylated recombinant chicken cystatin and the use thereof, US Patent, 7078488 B2 (2006).

[51] A. Anastasi, M.A. Brown, A.A. Kembhavi, M.J.H. Nicklin, C. A. Sayers, D.C. Sunter, et al., Cystatin, a protein inhibitor of cysteine proteinases, Improved purification from egg white, characterization, and detection in chicken serum, Biochem. J. 1983 (211) 129-138.

[52] K. Gołąb, J. Gburek, K. Juszczyńska, T. Trziszka, A. Polanowski, A way of stabilization of monomeric form of cystatin from egg white, Przemysł Chemiczny 91 (5) (2012) 174-179. (in Polish)

[53] J.A. Aarli, Role of cytokines in neurological disorders, Cur. Med. Chem. 10 (2003) 1931-1937.

[54] L. Steinman, Nuanced roles of cytokins in three major human brain disorders, J. Clin. Invest. 118 (2008) 3556-3563. 
[55] M. Janusz, K. Starościk, M. Zimecki, Z. Wieczorek, J. Lisowski, Chemical and physical characterization of a proline-rich polypeptide from sheep colostrum, Biochem. J. 199 (1981) 9-15.

[56] M. Kruzel, M. Janusz, J. Lisowski, R.V. Fischleigh, J.A. Georgiades, Towards an understanding of biological role of Colostrinin ${ }^{\circledR}$ peptides, J. Mol. Neurosci. 17 (2001) 379-389.

[57] A. Polanowski, A. Zabłocka, A. Sosnowska, M. Janusz, T. Trziszka, Immunomodulatory activity accompanying chicken egg yolk immunoglobulin Y, Poultry Science 91 (2012) 3091-3096.

[58] A. Polanowski, A. Sosnowska, A. Zabłocka, M. Janusz, T. Trziszka, Immunologically active peptides that accompany hen egg yolk IgY-separation and identification, Biol. Chem. (2013). DOI: 10.1515/hsz-2012-0337.

[59] S.H. Zeisel, Choline: Needed for normal development of memory, J. Am. Coll. Nutr. (5 Suppl.) (2000) 528S-531S.

[60] L.D. Miller, The benefits of lecithin on cardiovascular disease, in: B.F. Szuhaj, W. van Nieuwenhuyzen (Eds.), Nutrition and Biochemistry of Phospholipds, AOCS Press, USA, 2003, pp.117-129.

[61] M.E Van Elswyk, Comparison of $n-3$ fatty acid sources in laying hen rations for improvement of whole egg nutritional quality_A review, Br. J. Nutr. 78 (1997) 61-69.

[62] A.P. Simopoulos, Human requirement for n-3 polyunsaturated fatty acid, Poultry Sci. 79 (2000) 961-970.

[63] A.P. Simopoulos, The importance of the ratio of omega-6/omega-3 essential fatty acids, Biomed. Pharmacother. 56 (2002) 365-379.

[64] N. Shapira, P. Weill, R. Loewenbach, Egg fortification with n-3 polyunsaturated fatty acids (PUFA): Nutritional benefits versus high n-6 PUFA western diets, and consumer acceptance, Isr. Med. Assoc. J. Apr. 10 (2008) 262-265.

[65] N. Bragagnolo, D.B. Rodriguez-Amaya, Comparision of the cholesterol content of Brazilian chicken and quail eggs, Journal of Food Composition an Analysis 16 (2003) 147-153.

[66] A.P. Simopoulos, Evolutionary aspects of the dietary omega - 6:omega-3 fatty acid ratio: Medical implications, in: A.P. Simopoulos, F. De Meester (Eds.), A Balanced Omega-6/Omega-3 Fatty Acid Ratio, Cholesterol and Coronary Heart Disease, World Rev Nutr Diet. Basel, Karger, 100 (2009) 1-21. DOI: 10.1159/000235706.

[67] S.Y. Oh, J. Ryue, C.H. Hsieh, D.E. Bell, Eggs enriched in omega-3-fatty acids and alterations in lipid concentrations in plasma and lipoproteins and in blood-pressure, Am. J. Clin. Nutr. 54 (1991) 689-695.

[68] J.T. Bigger, T. El-Sherif, Polyunsaturated fatty acids and cardiovascular events: A fish tale, Circulation 103 (2001) 623-625.

[69] R. Uauy, A.D. Dangour, Nutrition in brain development and aging: Role of essential fatty acids, Nutr. Rev. 64 (5) (2006) 24-33.

[70] S.M. Innis, Dietary omega 3 fatty acids and the developing brain, Brain Research 1237 (2008) 35-43.

[71] C.J. Van Gool, M.P. Zeegers, C. Thijs, Epidemiology and health services research, Oral essential fatty acid supplementation in atopic dermatitis-A meta-analysis of placebo-controlled trials, British Journal of Dermatology 150 (2004) 728-740.

[72] E. Siepka, Ł. Bobak, T. Trziszka, Fractionation of egg yolk to obtain preparations enriched in biologically active substances, ŻYWNOŚĆ. Nauka. Technologia. Jakość 6 (73) (2010) 158-167

[73] M. Schreiner, H.W. Hulan, E. Razzazi-Fazeli, J. Böhm, C. Iben, Feeding laying hens seal blubber oil effects on egg yolk incorporation, stereospecific distribution of omega-3 fatty acids, and sensory properties, Poultry Science 84 (2004) 462-473.

[74] H. Bojarowicz, B. Woźniak, Polyunsaturated fatty acids and their influence on skin condition, Problemy Higieny $i$ Epidemiologii 89 (4) (2008) 471-475.

[75] N.M. Lewis, S. Seburg, N.L. Flanagan, Enriched eggs as a source of n-3 polyunsaturated fatty acids for humans, Poultry Science 79 (2000) 971-974.

[76] M. Sari, M. Akşit, M. Özdoğan, H. Basmacioğlu, Effect of addition of flaxseed to diets of lying hens on some production characteristic, levels of yolk and serum cholesterol, and fatty acid composition of yolk, Archiv für Geflugelkunde 66 (2002) 75-79.

[77] S. Tronina, D. Augustyn, Z. Dobrzański, D. Jamroz, S. Kukla, M. Mazurkiewicz, Dodatek paszowy dla drobiu, zwłaszcza dla kurcząt brojlerów i kur nośnych (Additive to a poultry feed, in particular to that for feeding young chickens and laying hens), PL Patent, 172908 (1997).

[78] S. Tronina, Z. Dobrzański, W. Buchowiecki, W. Gołąb, A. Grzelak, R. Iwanyszczuk, et al., Dodatek mineralno-thuszczowy do pasz (Minerals and fat containig fodder additive), PL Patent 182963 (2002).

[79] M. Eren, S. Gezen, G. Deniz, F. Orhan, Effect of liquid humate supplemented to drinking water on performance and eggshell quality of hens in different laying periods, Revue de Médicine Vétérinaire 159 (2008) 91-95.

[80] S. Kucukersan, K. Kucukersan, I. Colpan, E. Goncuoglu, Z. Reisli, D. Yesilbag, The effects of humic acid on egg production and egg traits of laying hen, Veterinarni Medicina 50 (2005) 406-410.

[81] Z. Dobrzański, T. Trziszka, E. Herbut, J. Krawczyk, P. Tronina, Effect of humic preparations on productivity and quality traits of eggs 300 from Greenleg Partridge hens, Annals of Animal Science 9 (2009) 165-174.

[82] T. Trziszka, Z. Dobrzański, M. Oziembowski, A. Jarmoluk, G. Krasnowska, An attempt to compare the quality of chicken eggs from cage system and ecological production, Archiv für Geflugelkunde 68 (2004) 1-6. 